\title{
Effect of tannin concentration on mycelial growth and development of Auricularia cornea
}

\section{Zhenyu Zhao}

Jilin Agricultural University

Dongyu Fan

Jilin Agricultural University

\section{Chen Zhang}

Jilin Agricultural University

\section{Fenghua Tian}

Jilin Agricultural University

\section{Bing Song}

Jilin Agricultural University

Chuanwen Jia

Jilin Agricultural University

Changtian Li ( $\square$ lct@jlau.edu.cn )

Jilin Agricultural University

Yu Li

Jilin Agricultural University

\section{Original article}

Keywords: Auricularia cornea, tannin stress, mycelial morphology, antioxidant enzymes

Posted Date: September 10th, 2020

DOI: https://doi.org/10.21203/rs.3.rs-73135/v1

License: (c) (i) This work is licensed under a Creative Commons Attribution 4.0 International License.

Read Full License 


\section{Abstract}

It is proved that the effect of tannin concentration on the mycelial growth of fungi. Auricularia cornea (white strain) were treated with different concentrations of tannins in petri-dishes and liquid shaking flasks. The growth rate of mycelium, the ratio of clamp connection, morphology of mycelium, biomass of mycelium and activity of antioxidant enzymes were determined. The results showed that different concentrations of tannin significantly decreased the rate of mycelium. However hign concentration of tannin stress increased the content of thiobarbituric acid in mycelia and had obvious time and concentration effects. Different antioxidant enzyme activities also had different responses to tannin stress. It provides theoretical basis for fungi to utilize and develop substrates containing tannin such as pine.

\section{Full Text}

Due to technical limitations, full-text HTML conversion of this manuscript could not be completed. However, the latest manuscript can be downloaded and accessed as a PDF.

\section{Tables}

Due to technical limitations, the tables are provided in the Supplementary Files section.

\section{Figures}
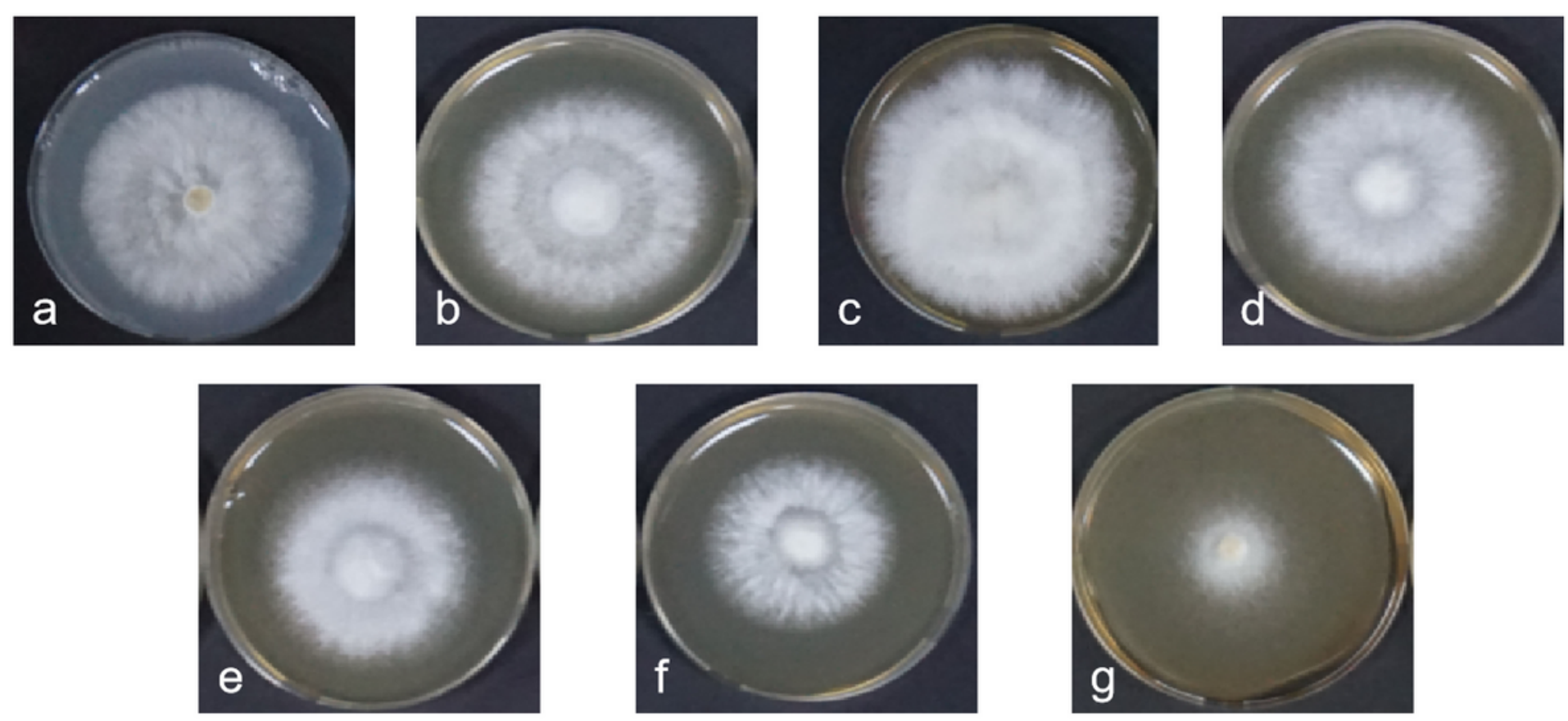

Figure 1 
Photos of A. cornea on different concentrations of tannins PDA medium

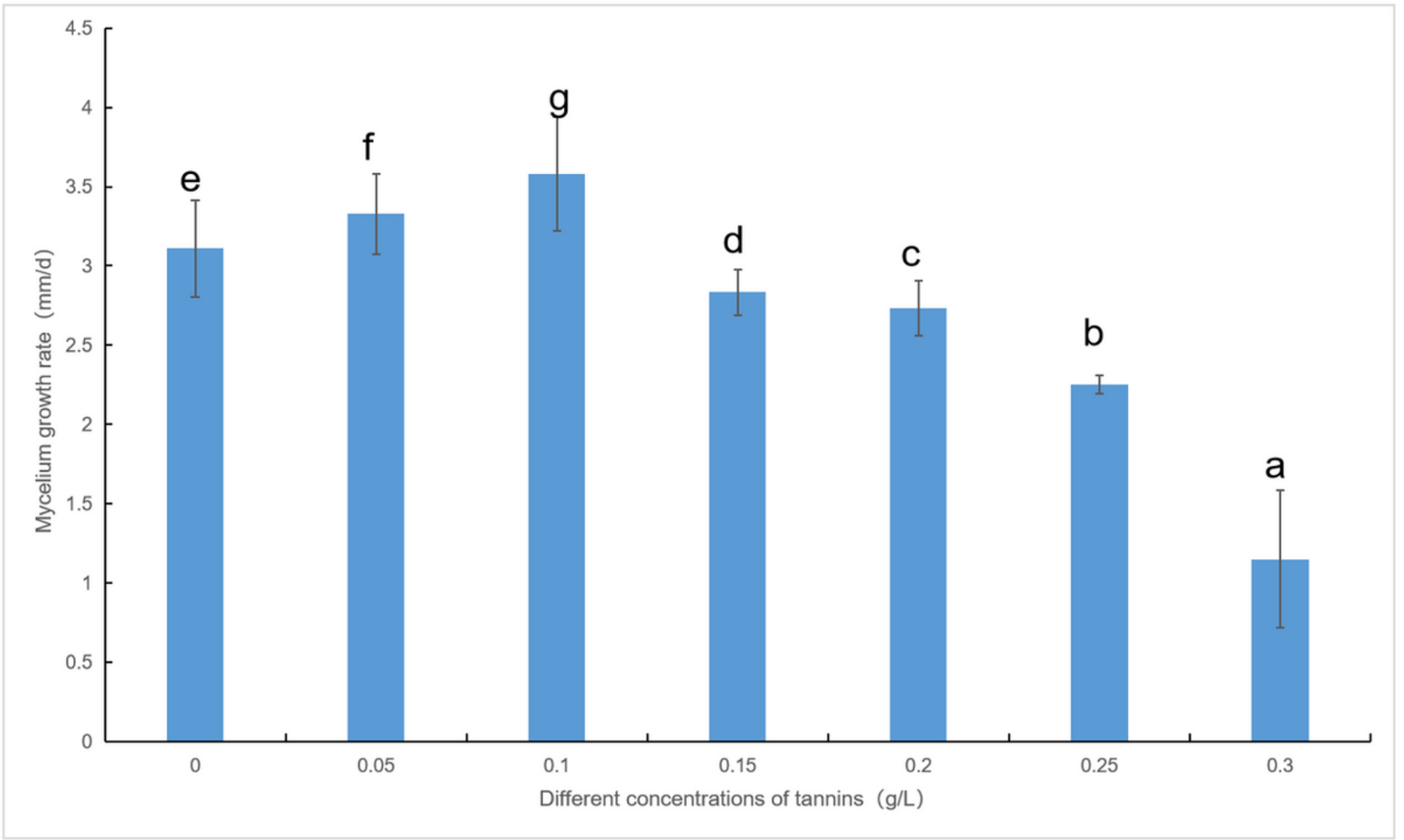

Figure 2

Effect of different concentrations of tannins on mycelial growth rate of A. cornea in PDA medium 


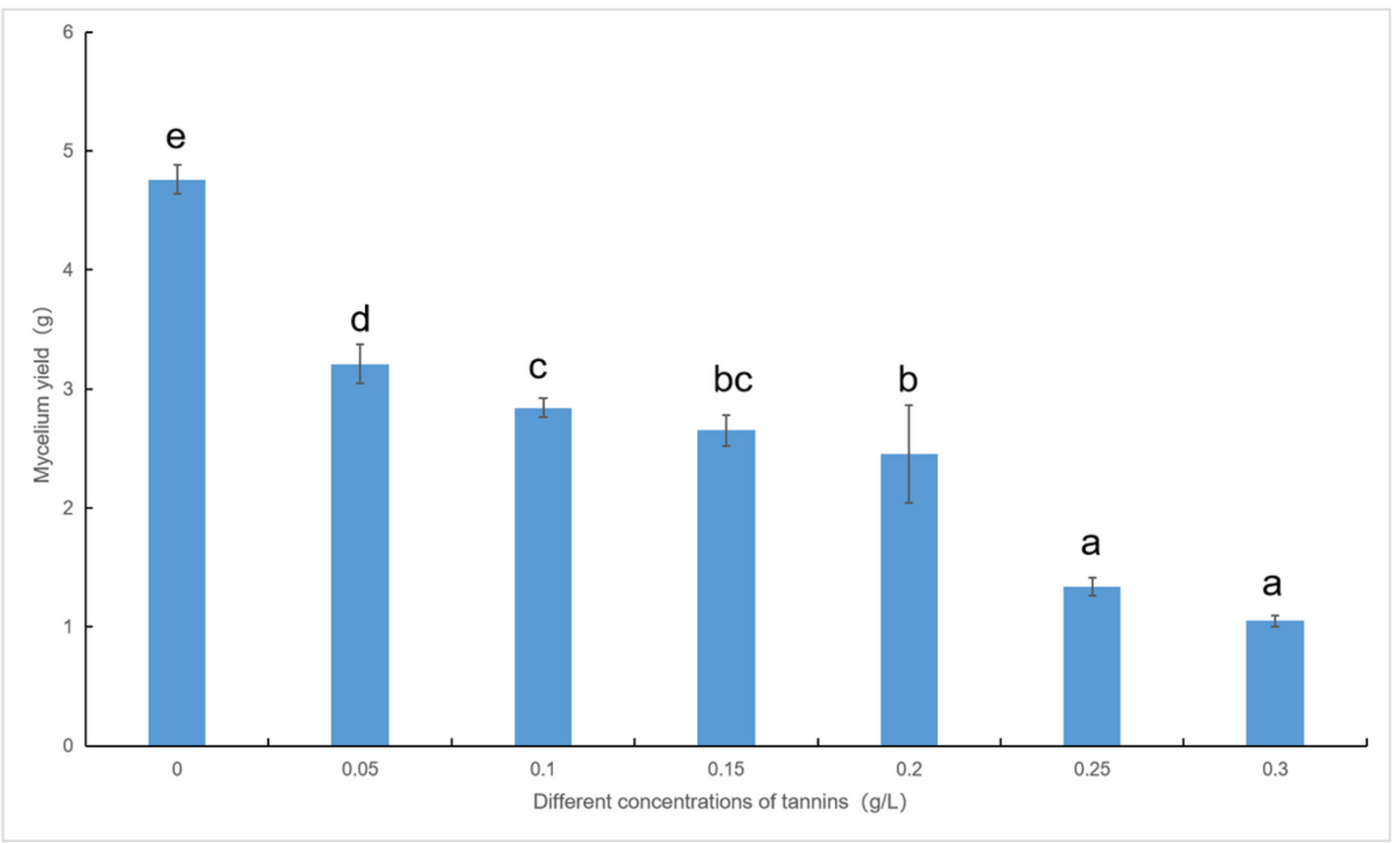

Figure 3

Effect of different concentrations of tannins on mycelial dry-weighted of A. cornea 


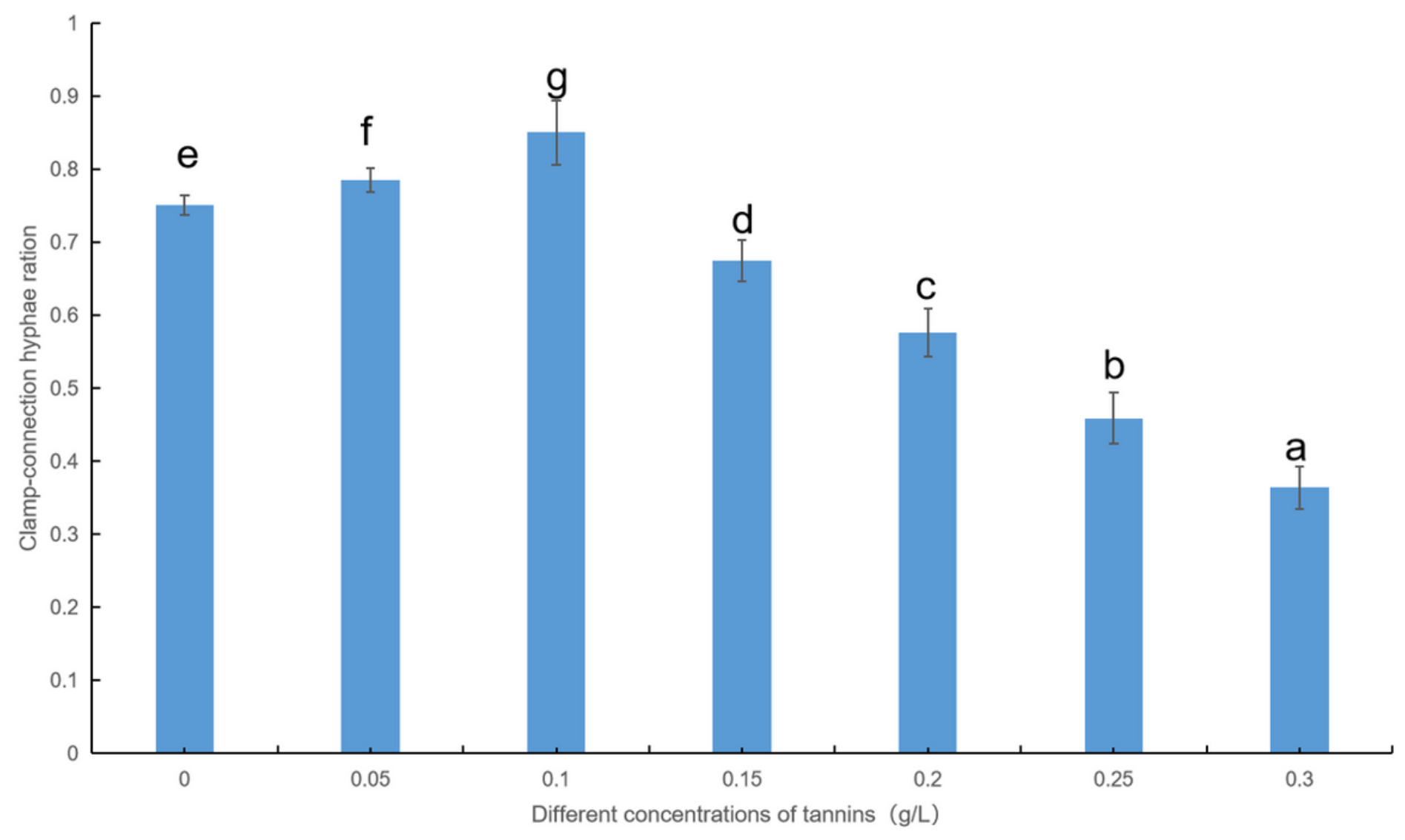

Figure 4

Effects of concentrations of tannins on the clamp-connection hyphae ration of A. cornea 


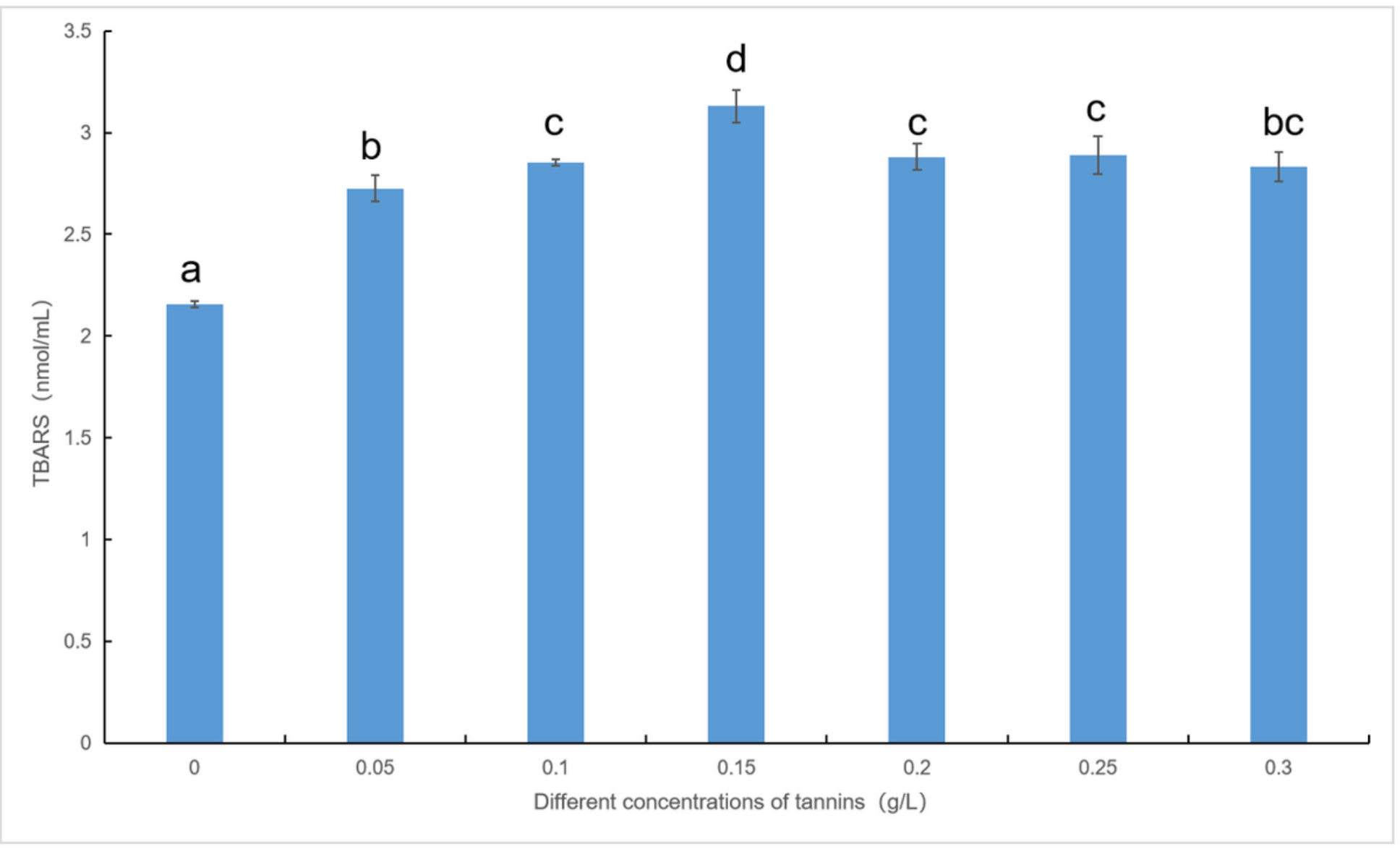

Figure 5

Effect of different concentrations of tannins on TBARS content of mycelial of A. cornea 


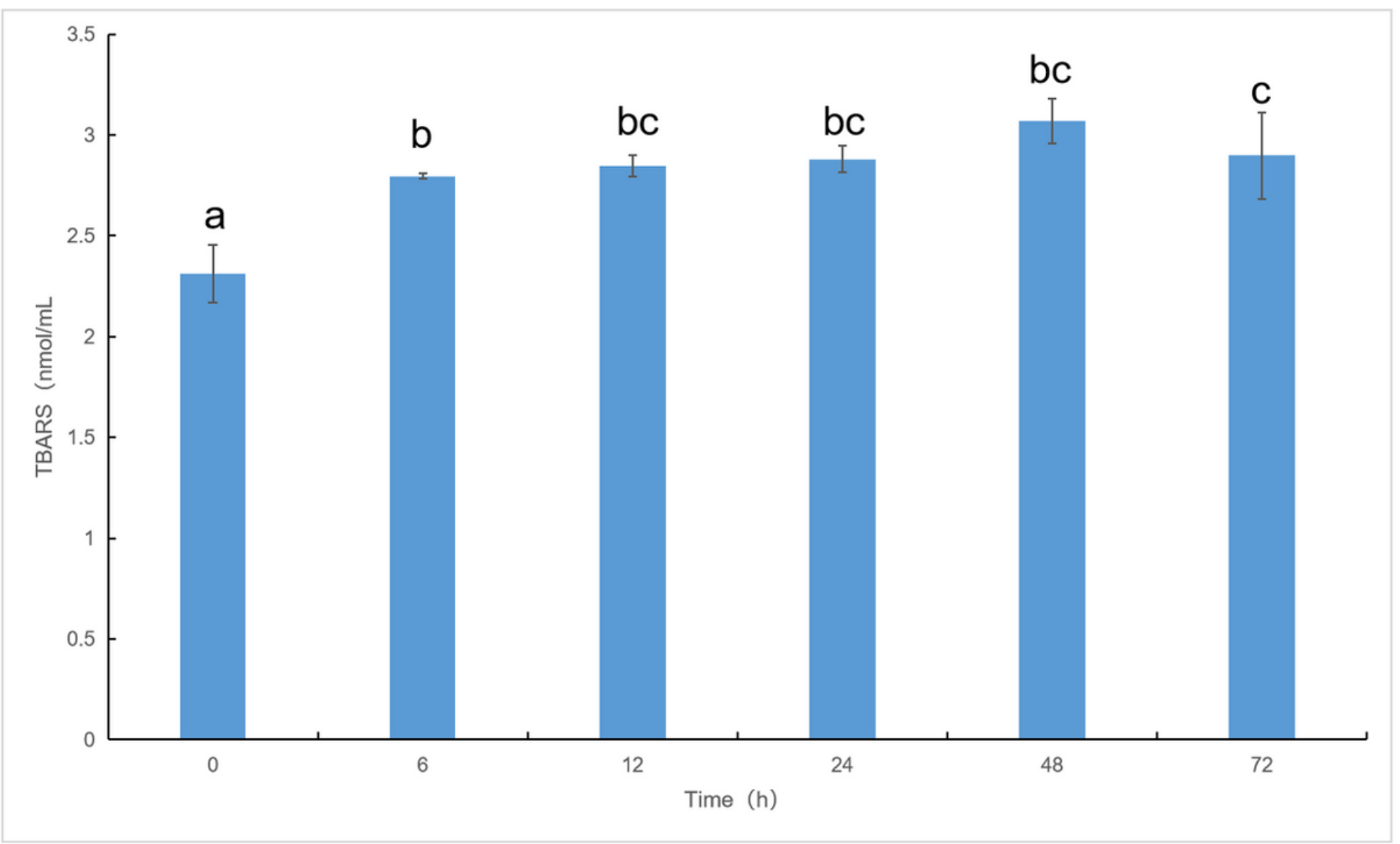

Figure 6

Effect of tannins on TBARS content of mycelial of A. cornea 


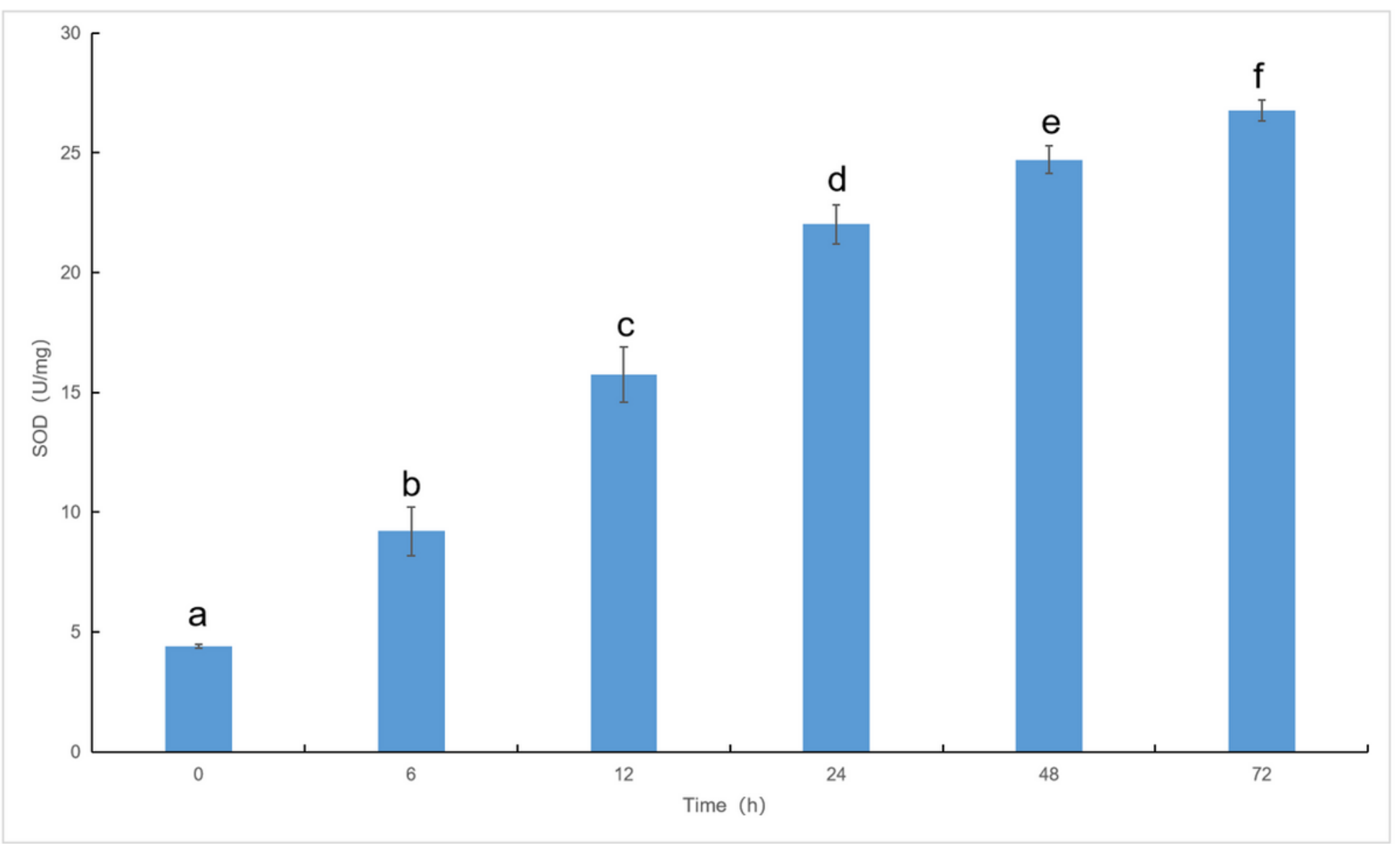

Figure 7

Effect of tannins on SOD activity of mycelial of A. cornea 


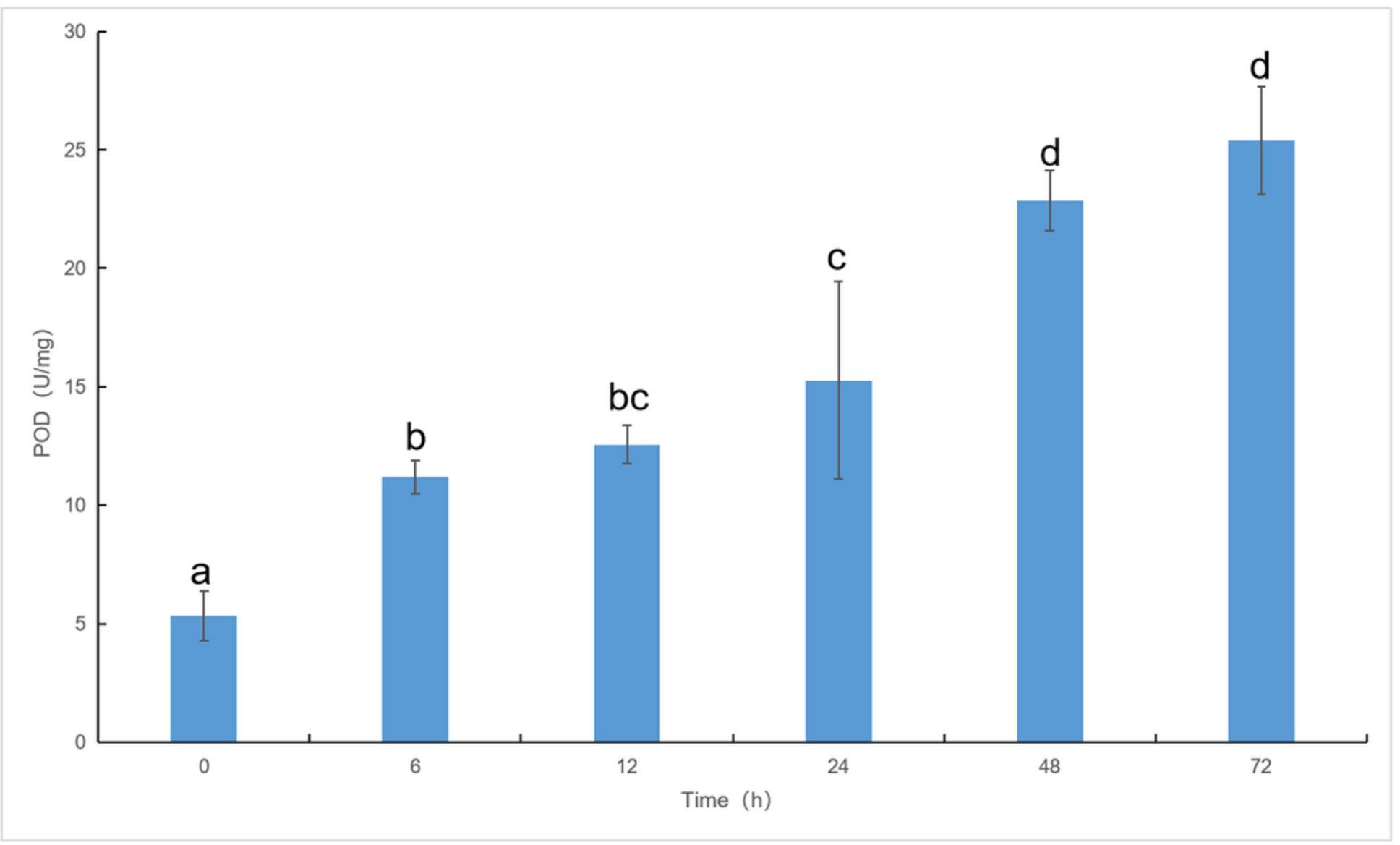

Figure 8

Effect of tannins on POD activity of mycelial of A. cornea 


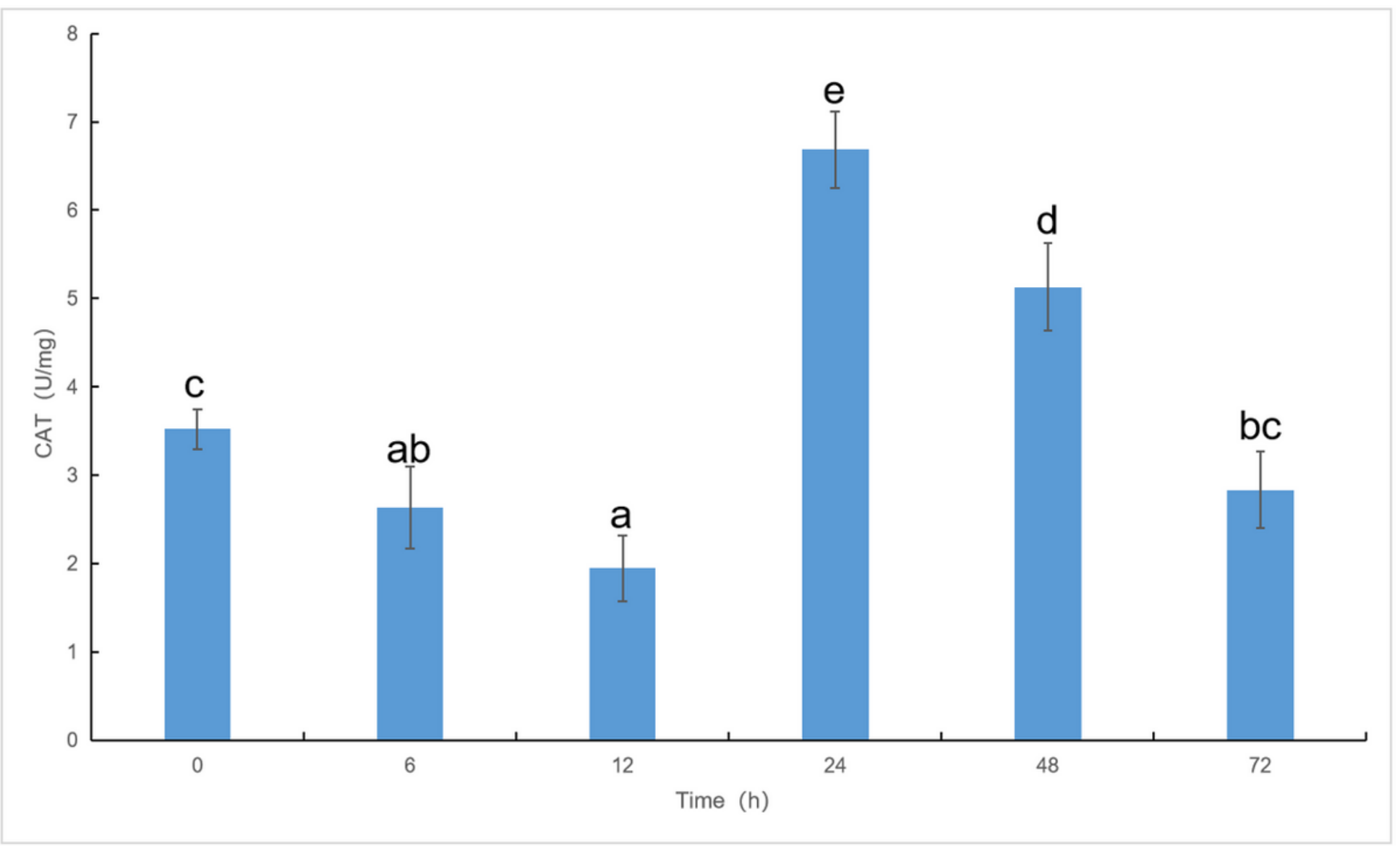

Figure 9

Effect of tannins on CAT activity of mycelial of A. cornea

\section{Supplementary Files}

This is a list of supplementary files associated with this preprint. Click to download.

- Table.pptx 